\title{
EFFECT OF GALLIC ACID ON THE FILLING QUALITY OF AN EPOXY RESIN - BASED ROOT CANAL SEALER
}

\author{
Ashraf Amin ${ }^{*}$
}

\begin{abstract}
Purpose: our study evaluated the effect of Gallic acid irrigation as a final rinse after sodium hypochlorite (NaOCL) irrigation on the filling Quality of an expoxy resin - based sealers.

Methods and Materials: Twenty single- rooted human teeth were prepared with the protaper system. The specimens were then divided into the following groups: 5.25\% NaOCL irrigation (NaOCL group) and $5.25 \% \mathrm{NaOCL}+10 \%$ gallic acid (gallic acid group). The root canals were filled using single cone technique with protaper $\mathrm{F}_{3}$ cones and Diapro - seal sealer, labeled with rhodamine B dye to allow analysis under a confocal laser scanning microscopy (CLSM). All Samples were sectioned at 3,5 and $7 \mathrm{~mm}$ form the apex and prepared for CLSM analysis. The Penetration segments of the canal were calculated at the apical, middle and coronal thirds. The Mann - Whitney statistical test was used at $5 \%$ significans level.

Results: higher percentage of gaps and voids were observed at all root thirds of the NaOCL group when compared to the gallic acid group $(\mathrm{P}<0.05)$. There was a significant increase in the penetration segment of gallic acid group at the coronal and middle root third when compared to the NaOCL group $(\mathrm{P}<0.05)$.

Conclusion: our in vitro results showed that the use of gallic acid as an antioxidant agent after $\mathrm{NaOCL}$ irrigation promoted a better interfacial adaptation and penetration of epoxy resin - based root canal sealers.
\end{abstract}

KEYWORDS: confocal laser scanning microscopy; Root canal filling; sodium hypochlorite; gallic acid.

\section{INTRODUCTION}

Sodium hypochlorite has a great antibacterial effect and the ability to dissolve organic tissues, so it is the most commonly used irrigant during endodontic treatment ${ }^{[1]}$.
The residual oxygen after the use of $\mathrm{NaOCL}$ irrigant on the inner dentinal walls disrupts the resin - based sealer polymerization ${ }^{[2]}$. Moreover, the mechanical properties of dentin like modulus of elasticity, microhardness and rigidity are adversely affected ${ }^{[3]}$.

\footnotetext{
* Lecture of Endodontics, Faculty of Dentistry, Kafr Elsheikh University.
} 
These problems can be overcomed by the use of antioxidant agents due to its ability to minimize the prejudicial effect of oxygen liberation after $\mathrm{NaOCL}$ use and its harmful effects on root canal sealers ${ }^{[4]}$.

Antioxidant agents break up free radicals, reacting and neutralizing NaOCL products. Gallic acid is an antioxidant that has been used as a neutralizing agents of $\mathrm{NaOCL}$, with promising results when used as a reducing agent for sodium hypochlorite - treated dentin ${ }^{[5]}$.

The aim of this study was to evaluate the effect of using gallic acid as a final rinse after using $\mathrm{NaOCL}$ on the filling quality of an expoxy - based sealer. $\mathrm{NaOCL}$ irrigation without antioxidant use was used for comparison. The null hypothesis tested was that there would be no difference in the filling Quality of epoxy resin- based root canal sealer when gallic acid was used after using NaOCL.

\section{MATERIALS AND METHODS}

\section{Tooth selection}

Completely-formed, single-rooted extracted human teeth (20 teeth total) were selected. The selected teeth should be free off root canal curvatures, cracks, calcification, cavities or restorations.

\section{Endodontic treatment}

The tooth crowns were sectioned with a diamond disc to obtain a standard root length of $15 \mathrm{~mm}$ for each sample. The root canals were prepared I $\mathrm{mm}$ short than the working length with protaper rotary instruments (Dentsply Maillefer, Switzerland) till $\mathrm{F}_{3}$ at a speed of $350 \mathrm{rpm}$ and torque of $3 \mathrm{~N}$. Then, the roots were randomly divided into two equal groups according to the irrigation method used into:

- $\mathrm{NaOCL}$ groups : irrigation with 5.25\% NaOCL and final rinse with saline

Gallic acid group: irrigation with 5.25\% NaOCL and final rinse with $10 \%$ gallic acid (sigma Aldrich, Bangalora, India). The $10 \%$ gallic acid was prepared by adding 10 gram of Gallic acid powder in $100 \mathrm{ml}$ of distilled water ${ }^{[5]}$.

At the beginning, and after each rotary file, the canals were irrigated with $3 \mathrm{ml}$ of $5.25 \% \mathrm{NaOCL}$ using a 5- ml plastic syringe and 30 gauge Navi tip needle (Ultradent products, south Jordan, USA).

After the $\mathrm{F}_{3}$ rotory file, the canals $[\mathrm{NaOCL}$ group] were rinsed with saline for 5 minutes. The canals of Gallic acid group were rinsed with $10 \%$ gallic acid for 5 minutes followed by $17 \%$ EDTA for 3 minutes and $10 \mathrm{ml}$ of saline solution again. All canals were dried with paper points.

\section{Root Canal Filling}

Diapro-seal (Diadent - Korea) was maniputed according to the manufacturer's instructions. Fluorescent rhodamin B dye (Sigma Aldrich, MO, USA) was added to the sealer mixture at a concentration of $0.1 \%{ }^{[6]}$ to allow visualization under a confocal laser microscope (Olympus, Tokyo, Japan). Size 30 rotary lentalo spiral was used for a uniform sealer distribution [Dentsply Maille Switzerland]. The root canals were filled using a single gutta percha cone $\mathrm{F}_{3}$ that matches the final rotary file and fitted to the working length after coating with additional Sealer. The excess filling was removed by a heated plugger.

Vertical compaction was applied to the orifice level. The obturated root samples were stored at $100 \%$ humidity and $37^{\circ} \mathrm{C}$ for one day to allow complete sealer setting.

\section{Specimans Prepartion for CLSM analysis}

Obturated roots were inserted in acryl, horizontally sectioned at 3,5 and $7 \mathrm{~mm}$ form the apex. So, 3 slices per root were obtained (cervical, Medium and apical root thirds). The spesimena were examined under a confocal microscope. The images were obtained with the absorption and emission wavelengths of 540 and $590 \mathrm{~nm}$, respectively, for rhodamine B. All images were anslysied by a blinded single evaluator with image J soft were (NIH, Bethesda, USA).The polygon selections tool of the image $\mathrm{J}$ soft was used to calculate the void area Percentage ${ }^{[7]}$. 
First, the total area of the canal was delimited for each sample, and the area values were registered. Then, the area of the gutta percha cone was measured. The sealer filled area of the canal was obtained by subtracting the gutta - percha area from the total area of the canal. The voids area was obtained as a percentage from the sealer filled area. A simildr method to the one proposed by moon et al [8] was used for penetration segment analysis. The segmented line tool was used (Image J software, NIH, USA). For each slice, first the total perimeter of the root canal was delimited, to obtain the length values. Then, the perimeter with in which sealer penetrates into the Dentinal tubules was measured. In this way, the sealer penetration segment was obtained as a percentage from the total perimeter.

\section{Statistical analysis}

The Mann - Whitney test was used for both gaps and root canal sealer penetration segment. Friedman test was used for intragroup comparisons between the different root slices. A 5\% level of statistical significance was applied.

\section{RESULTS}

After analyzing the area of voids and gaps (Table 1), the NaOCL group showed a significantly higher percentage of voids and gaps when compared to the gallic acid group in the different root slices $(\mathrm{p}<0.05)$. the intra group analysis showed a significant difference only for the NaOCL group where there was a higher percentage of voids in the cervical third when compared to the apical third $(\mathrm{P}<0.05)$.

Regarding the root canal sealer penetration segment, the NaOCL group showed a lower segment when compared to the gallic acid group in the coronal and middle root third $(\mathrm{P}<0.05)$. No significant differences in the apical third were observed between the groups $(\mathrm{P}<0.05)$ (table2). Intra group also demonstrated no significant differences between root thirds $(\mathrm{P}<0.05)$. Representive images of each group can be observed in figures; 1 and 2 .

TABLE (1) Mean (SD) values of percentage (\%) of voids \&gaps in the root canal filled teeth:

\begin{tabular}{|c|c|c|c|c|}
\hline Groups & Coronal & Middle & Apical & Over all \\
\hline NaOCL & $30(17.3)^{\mathrm{Aa}}$ & $19(11.3)^{\mathrm{Aab}}$ & $10.2(5.7)^{\mathrm{Ab}}$ & $20.3(14.6)^{\mathrm{A}}$ \\
\hline Gallic acid & $5.7(2.6)^{\mathrm{Bb}}$ & $4.1(2.4)^{\mathrm{Ba}}$ & $4.5(2.5)^{\mathrm{Ba}}$ & $4.8(2.4)^{\mathrm{B}}$ \\
\hline
\end{tabular}

Different capital letters in a column indicate statistically significant differences between the groups: different lowercase in the row indicate statistically significant differences between root thirds within the groups.

TABLE (2) mean (SD) values of percentage (\%) of penetration segment in the root canal filled teeth:

\begin{tabular}{|c|c|c|c|c|}
\hline Groups & Coronal & Middle & Apical & Over all \\
\hline NaOCL & $54.3(29.8)^{\mathrm{Aa}}$ & $55.2(10.2)^{\mathrm{Aa}}$ & $47.2(38.3)^{\mathrm{Aa}}$ & $51.5(23.4)^{\mathrm{A}}$ \\
\hline Gallic acid & $82.5(21.3)^{\mathrm{Ba}}$ & $83.1(21.3)^{\mathrm{Ba}}$ & $45.8(40.7)^{\mathrm{Aa}}$ & $66.8(34.3)^{\mathrm{B}}$ \\
\hline
\end{tabular}

Different capital letters in a column indicate statistically significant differences between the groups: different lowercase in the row indicate statistically significant differences between root thirds within the groups. 


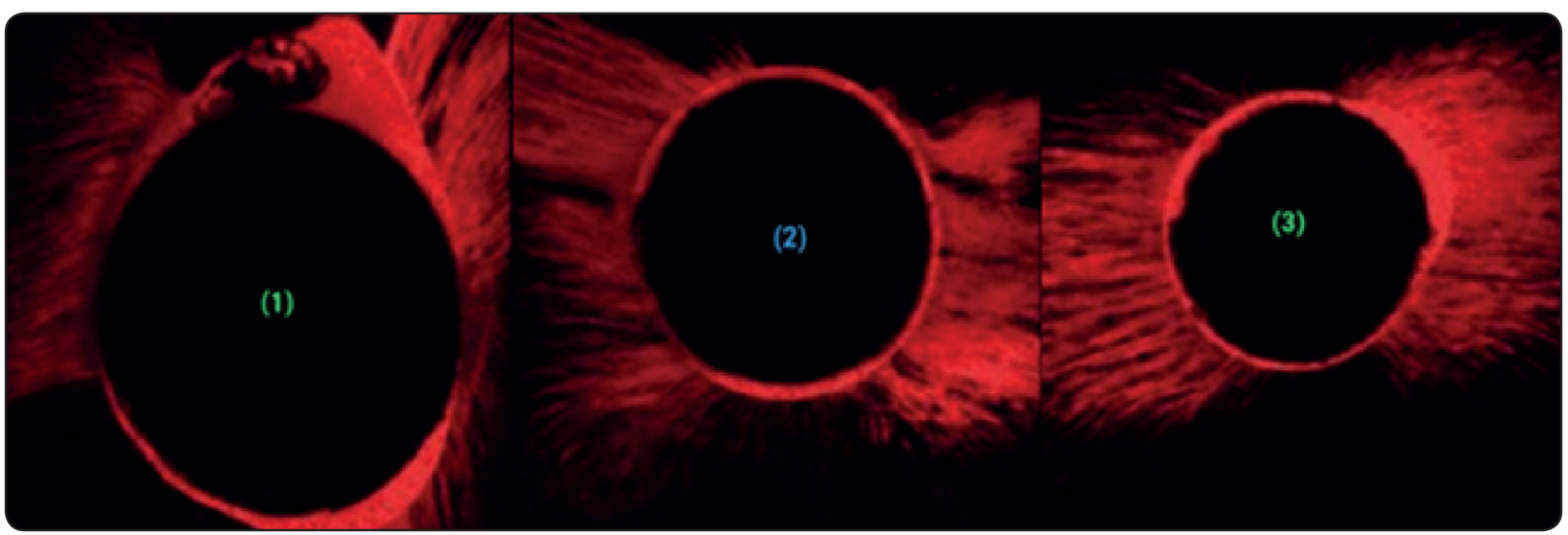

Fig. (1). Representative CLSM images (magnification 10x) of the root slices irrigated with 5,25\% NaOCL at the (1) coronal; (2) middle; (3) apical root third.

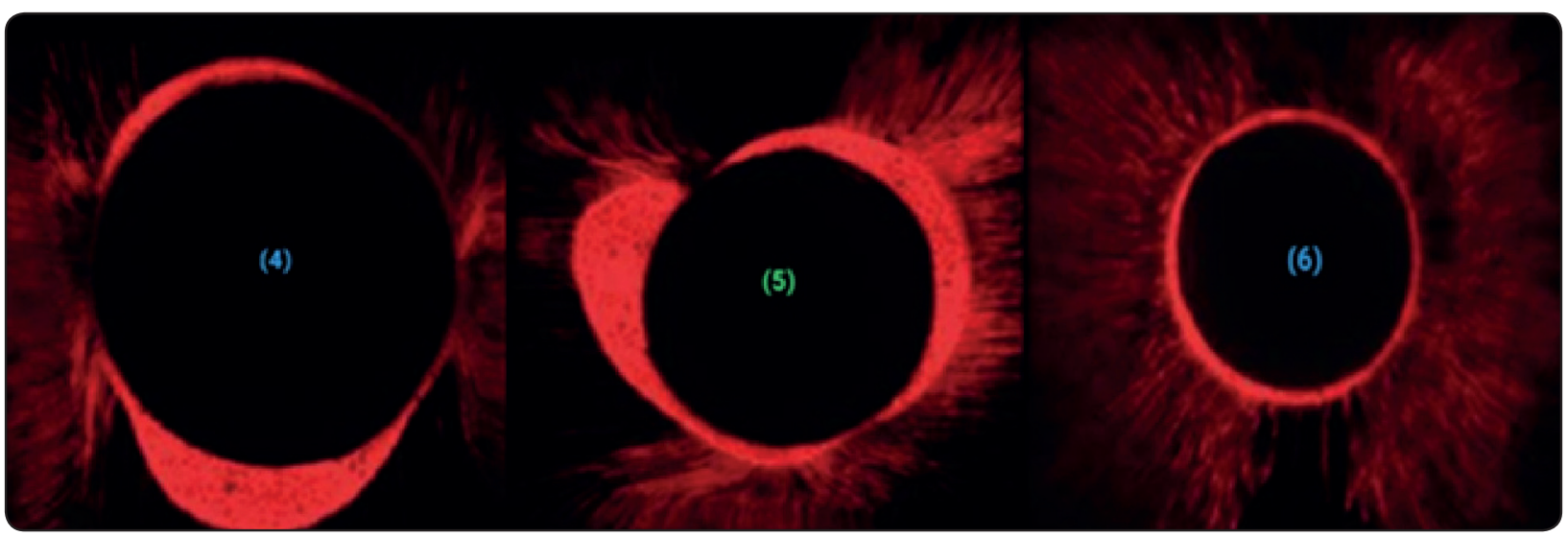

Fig. (2). Representative CLSM images (magnification 10x) of the root slices irrigated with 5,25\%NaOCL+10\% gallic acid at the (1) coronal;(2) middle;(3) apical root third.

\section{DISCUSSION}

Polymerization shrinkage of root canal sealer upon setting lead to gaps between the sealer and root dentin, these gaps allow micro leakage and subsequent bacterial invasion ${ }^{[9]}$. In this study, none of tested irrigation protocols at neither of the root thirds, provided a void and gap free obturation.

This result is in accordance with previous investigations ${ }^{[10-12]}$. However, the percentage of combined voids and gaps in obturated canals were significantly higher for the sodium hypochlorite group when compared to the gallic acid group all root sections. So, the first null hypothesis was rejected.
The optimal filling gap- free obturation of the chemo mechanically prepared root canal space is associated with more success rate of primary endodontic treatment ${ }^{[13]}$. However other studies demonstrated that void - free obturation is a challenge whatever the abturation technique used ${ }^{[7,13]}$.

Dia pro- seal is an epoxy resin-based sealer, and it was used in this study due to its acceptable physicochemical properties, biocompatibility, sealing ability and economic price ${ }^{[14]}$. The root canal sealer was applied by a rotary lentulo spiral which provided a better sealer wettability and distribution. A previous study demonstrated that the sealer distribution is not affected by sealer placement method ${ }^{[15]}$. 
It has been demonstrated that voids and gaps formation inside irregularly shaped canals is higher when using a single cone technique ${ }^{[16]}$.

In addition, single cone technique associated with a higher percentage of sealer and lower of the core material, especially in the cervical third of the oval - shaped canals ${ }^{[17]}$. Since gallic acid is potent antioxidant agent, the lesser formation of gaps and voids observed at gallic acid group, in cervical, middle and apical root thirds, compared to sodium hypochlorite group. Neutralization of sodium hypochlorite on the root dentin promoted by the final rinse with gallic acid. This neutralization allows the complete polymerization of resin-based sealers ${ }^{[4]}$. The gallic acid group provided a higher penetration segment on coronal and middle root thirds, compered to the sodium hypochlorite group since oxygen molecules inhibits resin infiltration into the tubules and inter - tubular dentin ${ }^{[18]}$, the oxidizing effect of NaOCL is likely to be responsible for the lack of sealer penetration on dentinal tubules of $\mathrm{NaOCL}$ group. The apical root slices did not differ between groups which may be due to decreased number of dentinal tubules, smaller dentinal diameter and tubular obliteration at the root apex ${ }^{[19]}$.

Furthermore smear layer removal in the coronal $\&$ middle thirds much more the apical one, and the decreased effect on irrigant delivery to the apical area may have some effect ${ }^{[20]}$.

A previous study reported that there is no relation between sealing ability and depth of intratubular sealer penetration, and accordingly, the percentage of penetration segment provides a more reliable data ${ }^{[21]}$.

It has been suggested that regardless of the depth of penetration, a higher penetration segment combined with antimicrobial properties allows the isolation of remaining bacteria ${ }^{[22,23]}$ and thus prevents microleakage also higher percentage of tubular penetration of the sealer provides a mechanical interlocking improving the root canal filling retention ${ }^{[24]}$. The results of the present study demonstrated that the percentage of penetration segment was higher when gallic acid was used therefore; the second null hypothesis was also rejected.

In this study, the obturation quality was assessed by using CLSM which have sereral advantages over (SEM) such as being simpler, easy and nondestructive sample processing, as well as lower tendency to produce artefacts ${ }^{[25]}$. Moreover the imags obtained by CLSM allows a quantitative data, unlike the qualitative scores commonly used in SEM imags, which may provide less reliability [26]. Rhodamine B dye is the standard fluorophore dye used, and it has been previously demonstrated that your use of in low concentrations $(0.1 \%)$ did not change the sealer properties, especially with epoxy resin-based sealer ${ }^{[6,27]}$.

The lack of a three-dimensional evaluation of the root canal filling might be a limitation of the analysis by CLSM, and micro-CT evaluations have been indicated as superior to the analysis of sectioned roots by digital imaging software ${ }^{[11]}$. A recent research ${ }^{[28]}$ obtained a higher incidence of voids after evaluation through stereomicroscopy, when compared with microscopic evaluation of sectioned roots. Moreover, Viapiana et al., [29] found a weak correlation between the assessment of sealing ability by micro CT\&CLSM, thus this study evaluated the incidence of voids and gaps on the root canal filling through CLSM, as similar researches previously assessed ${ }^{[6,10]}$.

\section{CONCLUSION}

Our invitro study showed the advantages of gallic acid irrigation after NaOCL irrigation in endodontic treatment with epoxy resin-based sealers using single cone technique, by creating less gap and void formation; we advocate further studies in the field. 


\section{REFERENCES}

1. Zehnder M. Root Canal Irrigants. J Endod. 2006; 32(5):389-398

2. Pascon FM, Kantovitz KR, Sacramento PA, Nobre-dosSantos M, Puppin-Rontani RM. Effect of sodium hypochlorite on dentine mechanical properties. A review. J Dent. 2009 Dec; 37(12):903-8.

3. Neelakantan P, Subbarao C, Subbarao CV, De-Deus G, Zehnder M. The impact of root dentine conditioning on sealing ability and push-out bond strength of an epoxy resin root canal sealer. Int Endod J. 2011 Jun;44(6):491-8.

4. Pimentel Corrêa AC, Cecchin D, de Almeida JF, Gomes BP, Zaia AA, Ferraz CC. Sodium Thiosulfate for Recovery of Bond Strength to Dentin Treated with Sodium Hypochlorite. J Endod. 2016 Feb;42(2):284-8.

5. Christopher SR, Mathai V, Nair RS, Angelo JM. The effect of three different antioxidants on the dentinal tubular penetration of Resilon and Real Seal SE on sodium hypochlorite-treated root canal dentin: An in vitro study. J Conserv Dent. 2016 Mar-Apr;19(2):161-5.

6. Hirai VHG, Machado R, Budziak MCL, Piasecki L, Kowalczuck A, Neto UXDS. Percentage of Gutta-Percha-, Sealer-, and Void-Filled Areas in Oval-Shaped Root Canals Obturated with Different Filling Techniques: A Confocal Laser Scanning Microscopy Study. Eur J Dent. 2020 Feb;14(1):8-12.

7. Moon YM, Shon WJ, Baek SH, Bae KS, Kum KY, Lee W. Effect of final irrigation regimen on sealer penetration in curved root canals. J Endod. 2010 Apr;36(4):732-6.

8. Ørstavik D, Nordahl I, Tibballs JE. Dimensional change following setting of root canal sealer materials. Dent Mater. 2001 Nov;17(6):512-9.

9. De-Deus G, Reis C, Di Giorgi K, Brandão MC, Audi C, Fidel RA. Interfacial adaptation of the Epiphany self-adhesive sealer to root dentin. Oral Surg Oral Med Oral Pathol Oral Radiol Endod. 2011 Mar;111(3):381-6.

10. Gulsahi K, Cehreli ZC, Onay EO, Tasman-Dagli F, Ungor M. Comparison of the area of resin-based sealer and voids in roots obturated with Resilon and gutta-percha. J Endod. 2007 Nov;33(11):1338-41.

11. Hammad M, Qualtrough A, Silikas N. Evaluation of root canal obturation: a three-dimensional in vitro study. J Endod. 2009 Apr;35(4):541-4.
12. Ng YL, Mann V, Rahbaran S, Lewsey J, Gulabivala K. Outcome of primary root canal treatment: systematic review of the literature -- Part 2. Influence of clinical factors. Int Endod J. 2008 Jan;41(1):6-31.

13. Naseri M, Kangarlou A, Khavid A, Goodini M. Evaluation of the quality of four root canal obturation techniques using micro-computed tomography. Iran Endod J. 2013 Summer;8(3):89-93.

14. Song YS, Choi Y, Lim MJ, Yu MK, Hong CU, Lee KW, Min KS. In vitro evaluation of a newly produced resin-based endodontic sealer. Restor Dent Endod. 2016 Aug;41(3):189-95.

15. Hall MC, Clement DJ, Dove SB, Walker WA 3rd. A comparison of sealer placement techniques in curved canals. J Endod. 1996 Dec;22(12):638-42.

16. Silva Almeida LH, Moraes RR, Morgental RD, Pappen FG. Are Premixed Calcium Silicate-based Endodontic Sealers Comparable to Conventional Materials? A Systematic Review of In Vitro Studies. J Endod. 2017 Apr;43(4): 527-535.

17. Keleş A, Alcin H, Kamalak A, Versiani MA. Micro-CT evaluation of root filling quality in oval-shaped canals. Int Endod J. 2014 Dec;47(12):1177-84.

18. Sadr S, Golmoradizadeh A, Raoof M, Tabanfar MJ. Microleakage of Single-Cone Gutta-Percha Obturation Technique in Combination with Different Types of Sealers. Iran Endod J. 2015 Summer;10(3):199-203.

19. Rueggeberg FA, Margeson DH. The effect of oxygen inhibition on an unfilled/filled composite system. J Dent Res. 1990 Oct;69(10):1652-8.

20. Mjör IA, Smith MR, Ferrari M, Mannocci F. The structure of dentine in the apical region of human teeth. Int Endod J. $2001 \mathrm{Jul} ; 34(5): 346-53$.

21. Kara Tuncer A, Tuncer S. Effect of different final irrigation solutions on dentinal tubule penetration depth and percentage of root canal sealer. J Endod. 2012 Jun; 38(6):860-3.

22. De-Deus G, Brandão MC, Leal F, Reis C, Souza EM, Luna AS, Paciornik S, Fidel S. Lack of correlation between sealer penetration into dentinal tubules and sealability in nonbonded root fillings. Int Endod J. 2012 Jul;45(7):642-51

23. Bolles JA, He J, Svoboda KK, Schneiderman E, Glickman GN. Comparison of Vibringe, EndoActivator, and needle irrigation on sealer penetration in extracted human teeth. J Endod. 2013 May;39(5):708-11. 
24. Reynolds, John \& Augsburger, Robert \& Svoboda, Kathy \& Jalali, Poorya. Comparing dentinal tubule penetration of conventional and 'HiFlow' bioceramic sealers with resin-based sealer: An in vitro study. Australian Endodontic Journal. 2020 46(3):387-393.

25. Mohammadian F, Farahanimastary F, Dibaji F, Kharazifard MJ. Scanning Electron Microscopic Evaluation of the Sealer-Dentine Interface of Three Sealers. Iran Endod J. 2017 Winter;12(1):38-42.

26. Furtado, Taiane \& de Bem, Igor \& Machado, Lucas \& Pereira, Jefferson \& Só, Marcus \& Rosa, Ricardo. Intratubular penetration of endodontic sealers depends on the fluorophore used for CLSM assessment. Microscopy research and technique. 2021; 84(2):305-312
27. Kim JA, Hwang YC, Rosa V, Yu MK, Lee KW, Min KS. Root Canal Filling Quality of a Premixed Calcium Silicate Endodontic Sealer Applied Using Gutta-percha Conemediated Ultrasonic Activation. J Endod. 2018 Jan;44(1): 133-138.

28. Rossetto DB, Fernandes SL, Cavenago BC, Duarte MA, Ordinola-Zapata R, de Andrade FB. Influence of the method in root canal filling using active lateral compaction techniques. Braz Dent J. 2014;25(4):295-301.

29. Viapiana R, Moinzadeh AT, Camilleri L, Wesselink PR, Tanomaru Filho M, Camilleri J. Porosity and sealing ability of root fillings with gutta-percha and BioRoot RCS or AH Plus sealers. Evaluation by three ex vivo methods. Int Endod J. 2016 Aug;49(8):774-82. 